\title{
Coordinative interaction of microcrystalline chitosan with oxovanadium (IV) ions in aqueous solution
}

\author{
Marta E Lichawska' ${ }^{1}$ Kazimiera H Bodek², Julia Jezierska ${ }^{3}$ and Aleksander Kufelnicki*
}

\begin{abstract}
Background: Chitosan, a non-toxic, biodegradable and biocompatible polysaccharide has attained great interest in pharmaceutical applications, as versatile drug delivery agent. Chitosan has been already shown to serve as vehicle for sustained drug release by chitosan-vanadium(IV) complex from a chitosan gel matrix. Therefore, chitosan gel proved to retain vanadium and preserve its insulin-mimetic efficacy. Nevertheless, there is a lack of reports concerning complexing equilibria in aqueous solution, in particular when using the more advantageous microcrystalline form of chitosan (MCCh). Microcrystalline chitosan shows a number of valuable features as compared with unmodified chitosan.

Results: Experimental studies on complexing interaction between a special form of biomaterial - microcrystalline chitosan as ligand, $L=$ MCCh, of two exemplary degrees of deacetylation DD (lower 79.8\%; higher 97.7\%) with $\mathrm{M}=$ oxovanadium (IV) ions have been carried out potentiometrically at four ligand-to-metal concentration ratios $(2: 1,5: 1,8: 1,10: 1)$. Among the five hydrolysis equilibria of $\mathrm{VO}^{2+}$ reported up to now in the literature, under the conditions of the present work i.e. aqueous solutions of ionic strength $I=0.1\left(\mathrm{KNO}_{3}\right)$ and temperature $25.0 \pm 0.1^{\circ} \mathrm{C}$, the predominating one was $(\mathrm{VO})_{2}(\mathrm{OH})_{2}{ }^{2+}$ formation: $\log \beta_{20-2}=-7.01(2)$. Analysis of potentiometric results permitted to note that degree of deacetylation does not essentially influence the coordination mode of the complexes formed. In the case of both the two DD values, as well as for all the ligand-to-metal ratios, formation of hydroxyl deprotonated $\mathrm{MLH}_{-1}$ and $\mathrm{ML}_{2} \mathrm{H}_{-2}$ moieties has been confirmed potentiometrically (log $\beta_{11-1}=-0.68(2)$ for $\mathrm{DD}=79.8 \%$ and $-0.68(2)$ for $\mathrm{DD}=97.7 \%, \log \beta_{12-2}=-7.64(6)$ for $\mathrm{DD}=79.8 \%$ and $-5.38(7)$ for $\left.\mathrm{DD}=97.7 \%\right)$.

Conclusion: Microcrystalline chitosan coordinates the vanadyl ions by the hydroxyl groups. Interaction of MCCh with $\mathrm{VO}^{2+}$ ions in aqueous solution occurs within $\mathrm{pH} 5-7$. Amounts of alkali excessive towards $-\mathrm{NH}_{2}$ are needed to deprotonate the $\mathrm{OH}$ groups. Deprotonation occurring at the chitosan hydroxyl groups permits a "pendant" or "bridge" model of coordination with VO(IV). Lack of complexation via deprotonation of amine groups, typical for simple cations and the molybdenum anion, has been indicated also by FTIR spectroscopy and EPR.
\end{abstract}

Keywords: Biomaterial, Microcrystalline chitosan, Vanadium (IV), Metal-polymer complexes, Equilibria in aqueous solution

\footnotetext{
* Correspondence: aleksander.kufelnicki@umed.lodz.pl

${ }^{1}$ Department of Physical and Biocoordination Chemistry, Faculty of

Pharmacy, Medical University of Łódź, 90-151 Łódź, Poland

Full list of author information is available at the end of the article
}

\section{Chemistry Central}

(C) 2014 Lichawska et al.; licensee Chemistry Central Ltd. This is an Open Access article distributed under the terms of the Creative Commons Attribution License (http://creativecommons.org/licenses/by/4.0), which permits unrestricted use, distribution, and reproduction in any medium, provided the original work is properly credited. The Creative Commons Public Domain Dedication waiver (http://creativecommons.org/publicdomain/zero/1.0/) applies to the data made available in this article, unless otherwise stated. 


\section{Background}

Chitosan is a polysaccharide composed of D-glucosamine (2amino-2-deoxy- $\beta$-D-glucose) and $N$-acetyl-D-glucosamine (2-acetamido-2-deoxy- $\beta$-D-glucose) (Figure 1$)$. This biopolymer is formed by partial deacetylation of chitin, the most widespread natural polysaccharide, found in shells of crustaceans. The molar D-glucosamine to $N$ acetyl-D-glucosamine ratio in the chitosan sample is an estimate of the so called degree of deacetylation (DD). The term chitosan is referred to chitin of DD $>60 \%$ [1-3]. The degree of deacetylation of the copolymer is usually within the range of $70.0 \%-95.0 \%$ [4-5].

This non-toxic, biodegradable and biocompatible material has attained great interest in pharmaceutical applications, as versatile drug delivery agent [1-3]. A valuable physicochemical modification of chitosan, used among others as excipient in drug formulations, is microcrystalline chitosan (MCCh), obtained in form of suspension, powder or granules [6-7]. A polymer of desired chemical properties is prepared by appropriate aggregation of the macromolecules from aqueous solutions of organic acids (via neutralization, coagulation and then precipitation of microcrystalline chitosan) [8]. During this process the polymer is also refined from low-molecular side products. Microcrystalline chitosan shows a number of valuable features as compared with unmodified chitosan: higher absorptivity, chelating capability, higher bioactivity, as well as ability of forming polymer films directly from water slurry. Similarly as it was the case with the previous forms of chitosan, MCCh may be proposed as an effective vehicle for the controlled vanadium release [3].

Vanadium (IV) plays a number of roles in the physiology of living systems. It is responsible for a number of processes, e.g. the inhibition of phosphate-metabolising enzymes such as phosphatases, ribonuclease and ATP-ases. The interaction of $\mathrm{VO}^{2+}$ with phosphates and nucleotides is of special interest in vanadium biochemistry [9]. The insufficiency of vanadium may, among other effects, lead to lowering the level of erythrocytes and pathologic increase of lipid level in blood. Recently, the medical significance of this element focuses on enhancing the treatment of type I diabetes mellitus (insulin-dependent) and also of type II (noninsulin-dependent) [10]. However, direct

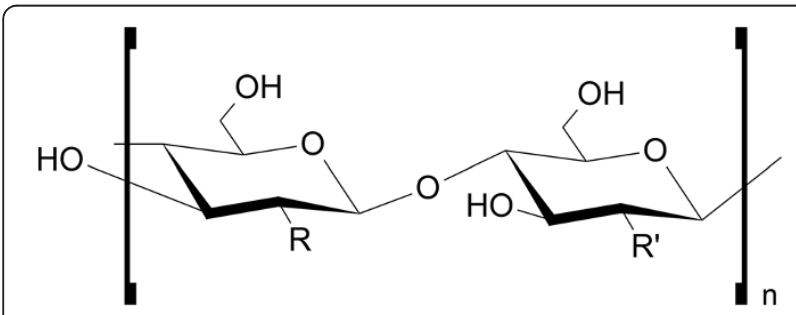

Figure 1 Structure of neutral chitosan $\left(\mathrm{R}=-\mathrm{NH}_{2}, \mathrm{R}^{\prime}=-\mathrm{NHOC}\right.$ $\mathrm{CH}_{3}$. In chitosan $\mathrm{R}$ predominates, in chitin every substituent is $\mathrm{R}^{\prime}$ ). application of vanadium by vanadyl sulphate has several undesired side-effects, such as gastrointestinal symptoms, anorexia and weight loss. Hence, it is necessary to elaborate a delivery mechanism suitable to be used in therapy. The most successful clinical trials were carried out with bis(maltolato)oxonanadium(IV) compounds (BMOV - bis-3-hydroxy-4-pyronato)oxovanadium(IV) and BEOV - bis(2-ethyl)-3-hydroxy-4-pyronato)oxovanadium(IV) but also with corresponding complexes of kojic acid (Hkoj - 3-hydroxy-6-hydroxymethyl-4-pyrone) and tropolone (Htrop - 2-hydroxy-2,4,6-cycloheptatrien-1-one) [11-15]. The first of them, BMOV, proved to be three times more effective than vanadyl sulfate as a glucose lowering agent. Recently also a number of other synthetic imidazole and pyridine based compounds of potential insulin-mimetic activity have been studied in solution [16-17]. Vanadium (IV) compounds mimic most of the biological effects of insulin in various cell types. They have been shown to increase glucose transport and oxidation (by that lowering glucose level in blood), to stimulate glycogen synthesis and to inhibit hepatic gluconeogenesis [18]. The anti-diabetic effect is probably attained via irreversible strong inhibition of the insulin receptor - one of the large class of tyrosine kinase receptors.

Unmodified chitosan has been already shown to serve as vehicle for sustained drug release by controlling the diffusion of chitosan-vanadium complex from a chitosan gel matrix. Therefore, chitosan gel proved to retain vanadium and preserve its insulin-mimetic efficacy [10]. Some earlier, kinetic and equilibrium studies on adsorption of $\mathrm{VO}^{2+}$ by chitosan were performed as well [19]. Up to now, the spectroscopic (only FTIR) investigation of the $\mathrm{VO}^{2+}$ - unmodified chitosan interaction was carried out for the final solid complex in comparison with pure chitosan [2]. Nevertheless, there is a lack of reports concerning complexing equilibria in aqueous solution, in particular when using the more advantageous microcrystalline form of chitosan (MCCh). Corresponding reactions of $\mathrm{MCCh}$ have been studied with other metalions in our previous papers [20-22]. It would be also interesting to investigate the DD influence on $\mathrm{VO}^{2+}-\mathrm{MCCh}$ complex formation. This effect has already been discussed in our latest paper with $\mathrm{Mo}(\mathrm{VI})$ [23].

\section{Results and discussion}

Analysis of potentiometric data and speciation models

The $\mathrm{pH}$ potentiometric data were elaborated in order to obtain appropriate speciation models and to determine the stability constants of complexes.

\section{Hydrolysis of $\mathrm{VO}^{2+}$}

The potentiometric studies of the vanadyl solution under exactly the same conditions as they were used in the potentiometric measurements with MCCh, described 
in later section, confirmed predomination of only the $(\mathrm{VO})_{2}(\mathrm{OH})_{2}{ }^{2+}$ hydroxo complex from among the species mentioned in the literature:

$$
2 \mathrm{VO}^{2+}+2 \mathrm{H}_{2} \mathrm{O} \rightleftharpoons(\mathrm{VO})_{2}(\mathrm{OH})_{2}{ }^{2+}+2 \mathrm{H}^{+} \log \beta_{20-2}=-7.01(2)
$$

The hydrolysis constant obtained was in good agreement with the corresponding corrected values reported recently: $-6.95[16,17]$, and in fairly agreement with the elder data: -6.67 [24], -6.72 [25], -6.88 [26]. On the other hand the simplest $\mathrm{VO}(\mathrm{OH})^{+}$hydroxo complex has been shown to occur in minor share up to $\mathrm{pH} \sim 5$, just like it was indicated in ref. [19]. The remaining hydroxo species reported in the literature: $\left[\mathrm{VO}(\mathrm{OH})_{3}\right]^{-}$and $\left[(\mathrm{VO})_{2}(\mathrm{OH})_{5}\right]^{-}$occur at $\mathrm{pH}>8[16]$, that is to say beyond the $\mathrm{pH}$ range of complexation with $\mathrm{MCCh}$.

\section{Complex formation with $\mathrm{VO}^{2+}$}

The potentiometric titrations in presence and absence of $\mathrm{L}=\mathrm{MCCh}$ corresponded to neutralization of the hydrogen ions in dependence of base equivalent $a$ ( $a=$ mmole of base $/ \mathrm{mmole}$ of ligand). Measurements started with neutralization of the excessive mineral acid $(a=-0.1-0)$ and then were continued by further alkalization of the $-\mathrm{NH}_{3}{ }^{+}$chitosan groups up to $a>1$ (Figure 2). As it follows also from Figure 2, the use of alkali needed to reach the end point in the samples with chitosan increased in presence of $\mathrm{VO}^{2+}$ - starting from ligand to metal ratio 10:1 up to 2:1. The values of $\mathrm{pH}$ were lower than for MCCh in absence of vanadyl ions. The parts of curves after $a \sim 1$ (end point of MCCh), the longer the higher is the part of vanadyl ion, are evidently connected with VO(IV) - MCCh complexation via the deprotonated hydroxyl groups but not the amine groups. This result is not surprising because it is known that the affinity of $\mathrm{V}^{\mathrm{IV}} \mathrm{O}^{2+}$ ion is much higher towards ligands with oxygen donors [27-29]. Coordinative interaction of oxido $\mathrm{V}^{\mathrm{IV}} \mathrm{O}^{2+}$ ion towards only nitrogen donors is very low and results in hydrolytic processes in acid and neutral solution. In turn, the titration curve corresponding to $\mathrm{VO}^{2+}$ in absence of ligand, showed a disturbance not far after the end point ( $a>$ ca 1.3), due to poor solubility of the forming aquohydroxo products.

Owing to the potentiometric results the proposed coordination reactions in the $\mathrm{M}=\mathrm{VO}^{2+}-\mathrm{L}=\mathrm{MCCh}$ system are shown in Equations (2) and (3) - charges omitted for clarity.

$$
\begin{aligned}
& \mathrm{M}+\mathrm{L}=\mathrm{MLH}_{-1}+\mathrm{H} \\
& \beta_{11-1}=\frac{\left[\mathrm{MLH}_{-1}\right][\mathrm{H}]}{[\mathrm{M}][\mathrm{L}]} \\
& \mathrm{M}+2 \mathrm{~L}=\mathrm{ML}_{2} \mathrm{H}_{-2}+2 \mathrm{H} \\
& \beta_{12-2}=\frac{\left[\mathrm{ML}_{2} \mathrm{H}_{-2}\right][\mathrm{H}]^{2}}{[\mathrm{M}][\mathrm{L}]^{2}}
\end{aligned}
$$

where: $\beta_{m l h}=\left[\mathrm{M}_{m} \mathrm{~L}_{l} \mathrm{H}_{h}\right] /[\mathrm{M}]^{m}[\mathrm{~L}]^{l}[\mathrm{H}]^{h}-$ cumulative stability constant; $m, l, h$ - number of metals (central ions), ligands and protons, respectively; concentrations in square bracket are equilibrium concentrations.

Except of the hydrolysis reaction mentioned in Equation 1, the calculations involved the protonation constant of MCCh under the same conditions as in the present experiments with $\mathrm{VO}^{2+}\left(\log \beta_{011}=6.50\right.$, that is in accordance with our previous data [23] and also with the literature [30]).

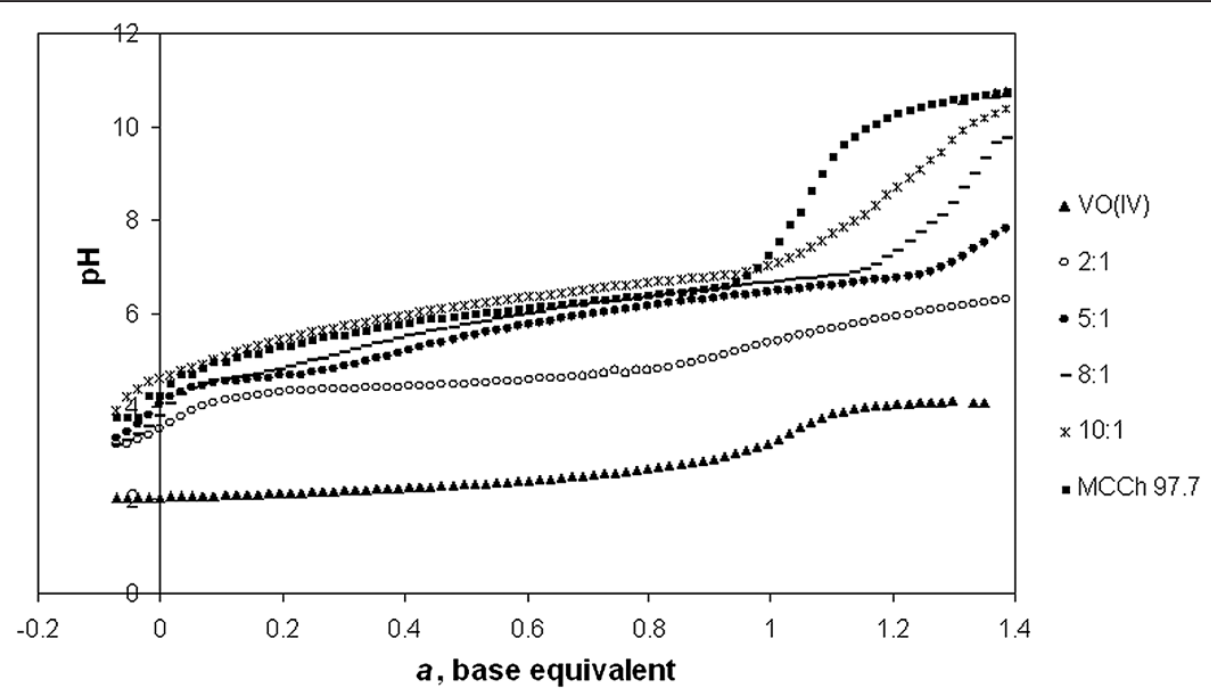

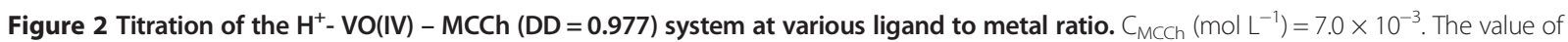
base equivalent $a=-0.1$ corresponds to $\mathrm{HNO}_{3}$ in excess as related to ligand. 
The next plot (Figure 3), directly originating from Hyperquad refinements, shows that the significant share of the accepted deprotonated species $\mathrm{MLH}_{-1}$ as well as lower share of the twice deprotonated $\mathrm{ML}_{2} \mathrm{H}_{-2}$ complex occurs at $\mathrm{pH} 5-7$. At lower $\mathrm{pH}$ the refinements indicate a small contribution (up to 10\%) of the $\mathrm{M}_{2} \mathrm{H}_{-2}=(\mathrm{VO})_{2}(\mathrm{OH})_{2}{ }^{2+}$ hydroxo complex (Figure 3). In turn, at $\mathrm{pH}$ higher than ca $7-7.5$, the increasing aggregation of chitosan makes impossible further accurate $\mathrm{pH}$ measurements. Finally, the present refinement results indicate donation via the deprotonated hydroxyl groups (Figure 4) just following $-\mathrm{NH}_{3}{ }^{+}$deprotonation. On the other hand, the specific structure of chitosan as polymer chain with a long distance between consecutive mers suggests that the higher accessibility of coordination sites occurs for hydroxyl donors from two neighbouring polymer chains in the $\mathrm{ML}_{2} \mathrm{H}_{-2}$ complex (Figure $4 \mathrm{~b}$ ). The above mentioned pattern involving deprotonated $\mathrm{OH}$ groups bonded to the $\mathrm{VO}^{2+}$ cation has already been described for $\mathrm{VO}^{2+} /$ carbohydrate complexes [9].

It is worthy to note that for the $\mathrm{MLH}_{-1}$ species the coordination mode does not essentially depend on the DD of chitosan (Table 1). However, at DD 97.7\% the stability constant of the $\mathrm{ML}_{2} \mathrm{H}_{-2}$ species is somewhat higher (less negative) than for DD $79.8 \%$. The latter difference is difficult to be interpreted because at $\mathrm{pH}>7$, i.e. at the end of the $\mathrm{pH}$ range used in calculations (and where the $\mathrm{ML}_{2} \mathrm{H}_{-2}$ species becomes predominating) as the titrations are evidently disturbed by increasing aggregation of MCCh of both DD's.

\section{Infrared spectra}

The FTIR spectra of free MCCh and of related MCCh samples in presence of $\mathrm{VO}^{2+}$ and at various $\mathrm{pH}$ are shown exemplary in Figures $5 \mathrm{a}$ and $\mathrm{b}$ for the lower DD value $-79.8 \%$.

In free chitosan the broad band (due to hydrogen bond interaction) visible from the high wavenumber side of spectrum $\left(\sim 3400 \mathrm{~cm}^{-1}\right)$ is assignable to the $\mathrm{O}-\mathrm{H}$ and $\mathrm{N}-\mathrm{H}$ stretching vibrations [2]. Moreover, the $\mathrm{C}-\mathrm{H}$ stretching bands could be identified as doublets at $2900 / 2850 \mathrm{~cm}^{-1}$ (Figure 5a). In presence of VO(IV) the spectra become poorly unresolved within this range, most probably as a result of overlapping by the vanadyl ion line and also due to the lower thickness and higher fragility of the films obtained in presence of $\mathrm{VO}^{2+}$.

In the medium IR range $600-1800 \mathrm{~cm}^{-1}$ the region $1400-1800 \mathrm{~cm}^{-1}$ is of particular interest. Our spectra of pure MCCh derived from thin films, much more distinct that the ones recorded from $\mathrm{KBr}$ pellets, showed both the so called amide I band at ca $1630 \mathrm{~cm}^{-1}$ (which is essentially the $\mathrm{C}=\mathrm{O}$ stretching vibration of the $-\mathrm{NHOC}-\mathrm{CH}_{3}$ group) [2] as well as the amide II band of the secondary amide groups and the deformation scissoring mode, $\delta\left(\mathrm{NH}_{2}\right)$, of the primary amine groups $-\mathrm{NH}_{2}-$ ca $1530 \mathrm{~cm}^{-1}$. As can be observed the two bands are well splitted and free of noise up to $\mathrm{pH}$ at least 5.5. In presence of $\mathrm{VO}(\mathrm{IV})$ the rise of $\mathrm{pH}$ resulted in lowering and deformation of the latter bands, also probable due to progressive deprotonation of the $-\mathrm{NH}_{3}{ }^{+}$and following aggregation of the MCCh chains - (ref. Figure 4b). The bands are only remaining in lowering intensity only at $\mathrm{pH} 3.54-6.44$. Characteristic that in presence of $\mathrm{VO}$ (IV) the spectra do not show any visible shift of the amide II band nor of the scissoring mode of the primary amine groups, $\delta\left(\mathrm{NH}_{2}\right)$. Such shifts towards higher wavenumbers have been already described for interaction of chitosan with other metals, like $\mathrm{Cu}(\mathrm{II}), \mathrm{Hg}(\mathrm{II})$ and $\mathrm{Ni}$ (II) [31-32]. Hence, this observation may be evidently connected with our previously discussed potentiometric titrations confirming rather complexation via the hydroxyl oxygens than the amine nitrogens.

An additional spectral IR line of pure $\mathrm{VO}^{2+}$ was shown in Figure 5b. Its special feature may be assigned to the low intensive, scarcely splitted band at ca $1000 \mathrm{~cm}^{-1}$, due to

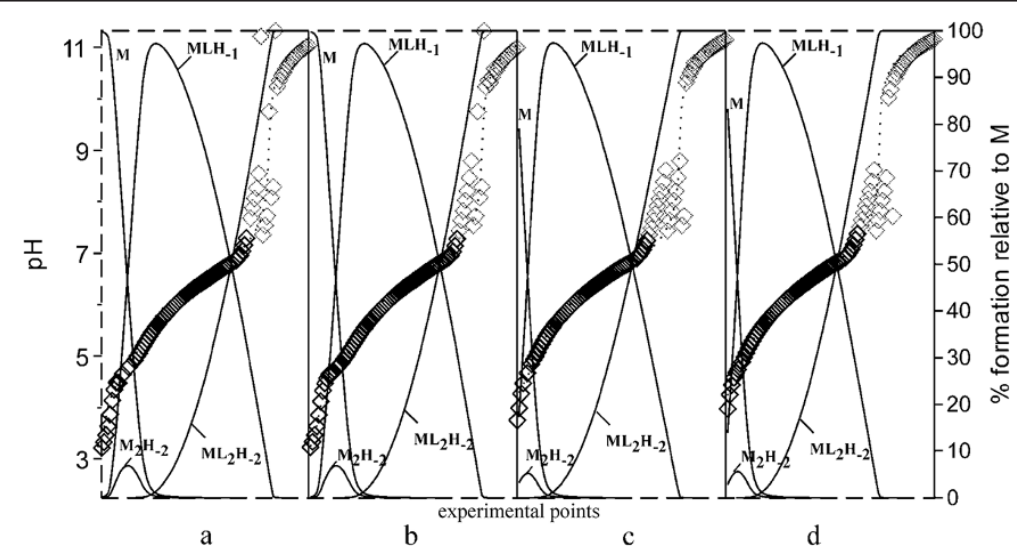

Figure 3 Titration curves (presented by square points) and species distribution of the complexes formed in $\mathrm{H}^{+}-\mathrm{VO}(\mathrm{IV})-\mathrm{MCCh}(\mathrm{DD}=0.977)$ system. $C_{\text {Mcch }}\left(\mathrm{mol} \mathrm{L}^{-1}\right)=7.0 \times 10^{-3}$. Ligand to metal ratio a) 2:1, b) 5:1, c) 8:1, d) 10:1. Dotted points correspond to the pH range of visible precipitation. 


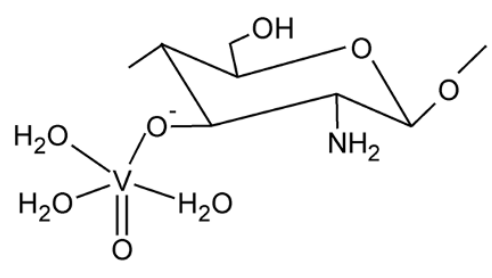

a

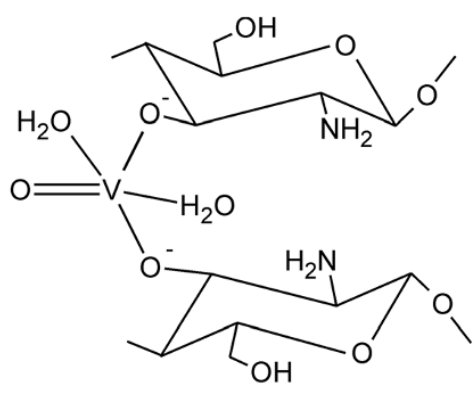

b

Figure 4 Simplified coordination scheme of $L=M C C h$ to $M=$ oxovanadium(IV) at neutral $p H:$ a) $\left.M L_{-1}, b\right) M L_{2} H_{-2}$.

the characteristic $\mathrm{V}=\mathrm{O}$ stretching vibration [3-9]. The visible disappearance of this band in presence of MCCh (starting from the lowest $\mathrm{pH} 3.54$, where potentiometry shows already the share of complexation) may be explained by strong hydrogen-bond interactions between free hydroxyl groups of the carbohydrate ligand and the oxo group of the metal center thus leading to diminution of the $\mathrm{V}=\mathrm{O}$ bond strength.

\section{Indications of EPR spectroscopy}

The EPR spectra of water frozen solutions of $\mathrm{VOSO}_{4}-$ chitosan system (Figure 6), exhibit eight line hyperfine splitting due to $\mathrm{I}\left({ }^{51} \mathrm{~V}\right) \mathrm{I}=7 / 2$. The parallel hyperfine lines are located symmetrically around $g \|=1.933$ (with $A \|$ $\left.180 \times 10^{-4} \mathrm{~cm}^{-1}\right)$ whereas the perpendicular lines around $g_{\perp}=1.977$ (with $A_{\perp}=\sim 70 \times 10^{-4} \mathrm{~cm}^{-1}$ ). The EPR parameters, $g \|<g_{\perp}$, correspond to axial symmetry of compressed tetragonal geometry of $\mathrm{VO}^{2+}$ complexes. On the other hand the relation $g \|<g_{\perp}<2.0023$ is an unambiguous proof of $d^{1}$ electron configuration of vanadium ion. The EPR $g$ and $\boldsymbol{A}$ tensor components corresponding to $H=\beta S$ $\boldsymbol{g} \boldsymbol{B}$ and $H=\boldsymbol{S} \boldsymbol{A} \boldsymbol{I}$ spin Hamiltonians of the $\mathrm{VO}(\mathrm{IV})$ complexes formed at various $\mathrm{pH}$ are almost similar to those observed for water solution of $\mathrm{VOSO}_{4}$. This indicates that amine nitrogen atoms of chitosan are not involved in $\mathrm{VO}$ (IV) coordination and supports that only oxygen donors

Table 1 Cumulative stability constants $\log \beta_{m / h}{ }^{a}$ of the VO(IV) - MCCh complexes

\begin{tabular}{|c|c|c|c|c|c|c|}
\hline Value of DD & $C_{\mathrm{L}} / C_{\mathrm{M}}$ & $\log \beta_{11-1}^{b}$ & $\log \beta_{11-1}{ }^{c}$ & $\log \beta_{12-2}^{b}$ & $\log \beta_{12-2}{ }^{c}$ & $\overline{\mathrm{pH} \text { range }}$ \\
\hline \multirow{8}{*}{$79.8 \%$} & \multirow{2}{*}{$2: 1$} & $-0.39(5)$ & \multirow{8}{*}{$-0.68(2)$} & $-4.48(23)$ & \multirow{8}{*}{$-7.64(6)$} & \multirow{8}{*}{$2.53-7.34$} \\
\hline & & $-0.26(5)$ & & $-4.18(24)$ & & \\
\hline & \multirow{2}{*}{$5: 1$} & $-0.82(3)$ & & $-7.81(16)$ & & \\
\hline & & $-0.80(4)$ & & $-7.59(8)$ & & \\
\hline & \multirow{2}{*}{$8: 1$} & $-0.90(5)$ & & $-8.11(10)$ & & \\
\hline & & $-0.87(4)$ & & $-7.43(10)$ & & \\
\hline & \multirow{2}{*}{$10: 1$} & $-0.99(6)$ & & $-7.83(26)$ & & \\
\hline & & $-0.98(6)$ & & $-8.06(11)$ & & \\
\hline \multirow{8}{*}{$97.7 \%$} & \multirow{2}{*}{$2: 1$} & $-0.53(4)$ & \multirow{8}{*}{$-0.68(2)$} & $-4.67(21)$ & \multirow{8}{*}{$-5.38(7)$} & \multirow{8}{*}{$3.18-7.38$} \\
\hline & & $-0.56(3)$ & & $-5.72(29)$ & & \\
\hline & \multirow{2}{*}{$5: 1$} & $-0.71(4)$ & & $-4.41(9)$ & & \\
\hline & & $-0.68(4)$ & & $-4.45(9)$ & & \\
\hline & \multirow{2}{*}{$8: 1$} & $-0.68(4)$ & & $-4.95(10)$ & & \\
\hline & & $-0.88(6)$ & & $-4.45(9)$ & & \\
\hline & \multirow{2}{*}{$10: 1$} & $-1.40(3)$ & & $-6.76(6)$ & & \\
\hline & & $-1.29(8)$ & & $-5.69(14)$ & & \\
\hline
\end{tabular}

a refer to the general reaction: $m\left(\mathrm{VO}^{2+}\right)+/ \mathrm{L}+h \mathrm{H} \rightleftharpoons(\mathrm{VO})_{m} \mathrm{~L}_{l} \mathrm{H}_{h}{ }^{2 m+h}$.

${ }^{\mathrm{b}}$ results from individual titrations.

cresults from comprehensive files of all titrations.

$T=25.0^{\circ} \mathrm{C}, I=0.1 \mathrm{~mol} \mathrm{~L}^{-1}\left(\mathrm{KNO}_{3}\right)$. Standard deviations in parentheses. $C_{\mathrm{L}}=$ total concentration of ligand; $C_{\mathrm{M}}=$ total concentration of $\mathrm{VO}^{2+}$. 


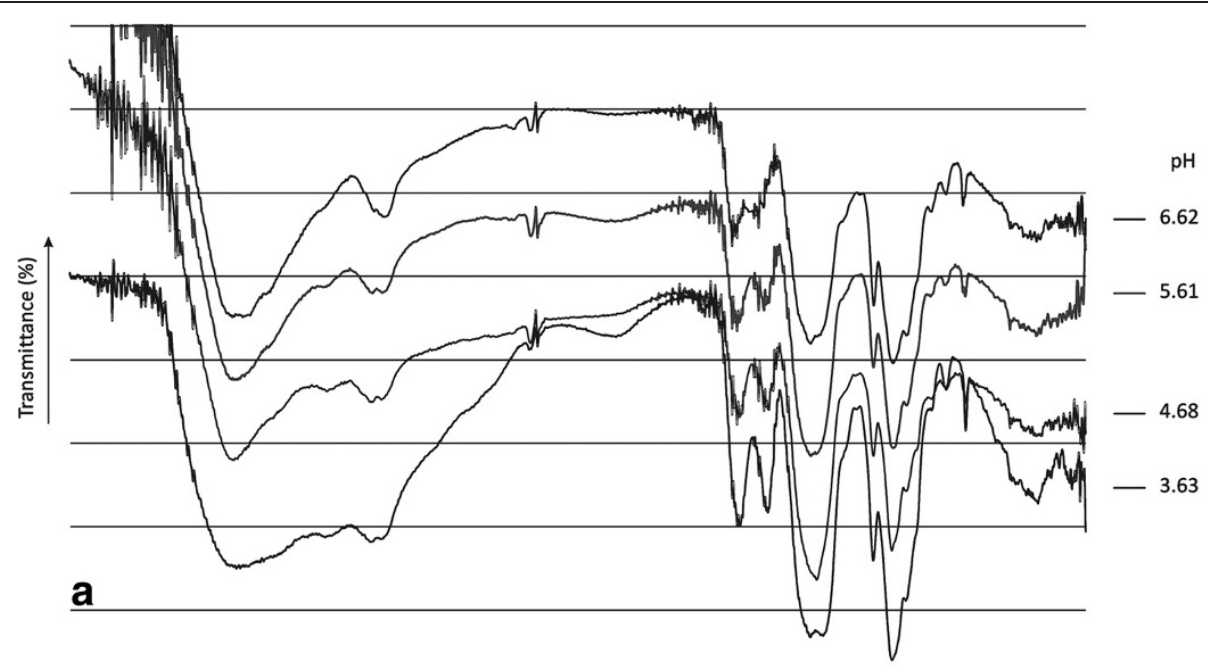

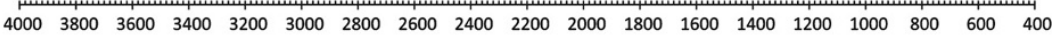
Wavenumber $\left(\mathrm{cm}^{-1}\right)$

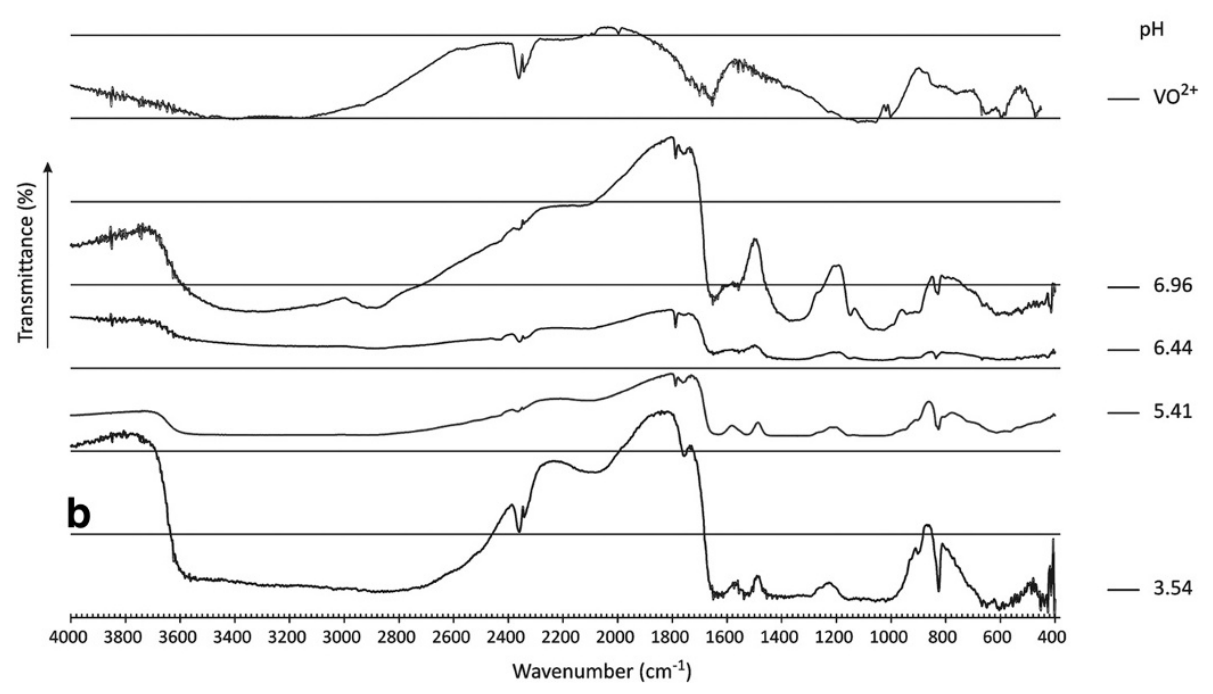

Figure 5 FTIR spectra obtained in thin polymer films of a) pure MCCh (DD 79.8\%) and b) MCCh in presence of $\mathrm{VO}^{2+}$ ions at various $\mathrm{pH}$. Comparative spectrum for $\mathrm{VO}^{2+}$ taken in $\mathrm{KBr}$ pellets.

of hydroxyl groups participate in VO(IV) complexation, as it has been already shown by the potentiometric results.

\section{Conclusions}

The studies show that MCCh interacts with oxovanadium (IV) in aqueous solution starting from pH 5. Then, the deprotonation of amine groups is followed by deprotonation of the hydroxyl groups, which leads to a higher use of alkali in the $\mathrm{pH}$-potentiometric titration with respect to chitosan alone, proportional to the part of vanadyl ion in the sample. Thus, the refinements based on potentiometric data confirm coordination via oxygen atoms from the deprotonated hydroxyl groups.
From the coordination modes accepted: $\mathrm{OH}$ deprotonated $\mathrm{MLH}_{-1}{ }^{-}$and twice $\mathrm{OH}$ deprotonated $\mathrm{ML}_{2} \mathrm{H}_{-2}{ }^{2-}$ species, the second one involves a moiety with one vanadyl binding two adjacent chitosan mers, most probably of two neighbouring polymer chains. Lack of complexation via deprotonation of amine groups, typical for simple cations and the molybdenum anion, has been indicated also by FTIR spectroscopy and EPR. It seems then quite understandable that the degree of deacetylation has no essential influence on the thermodynamical stability of the $\mathrm{MLH}_{-1}{ }^{-}$species predominating within the main range of complexation. On the other hand the second deprotonated species i.e. $\mathrm{ML}_{2} \mathrm{H}_{-2}{ }^{2-}$ is formed when the 


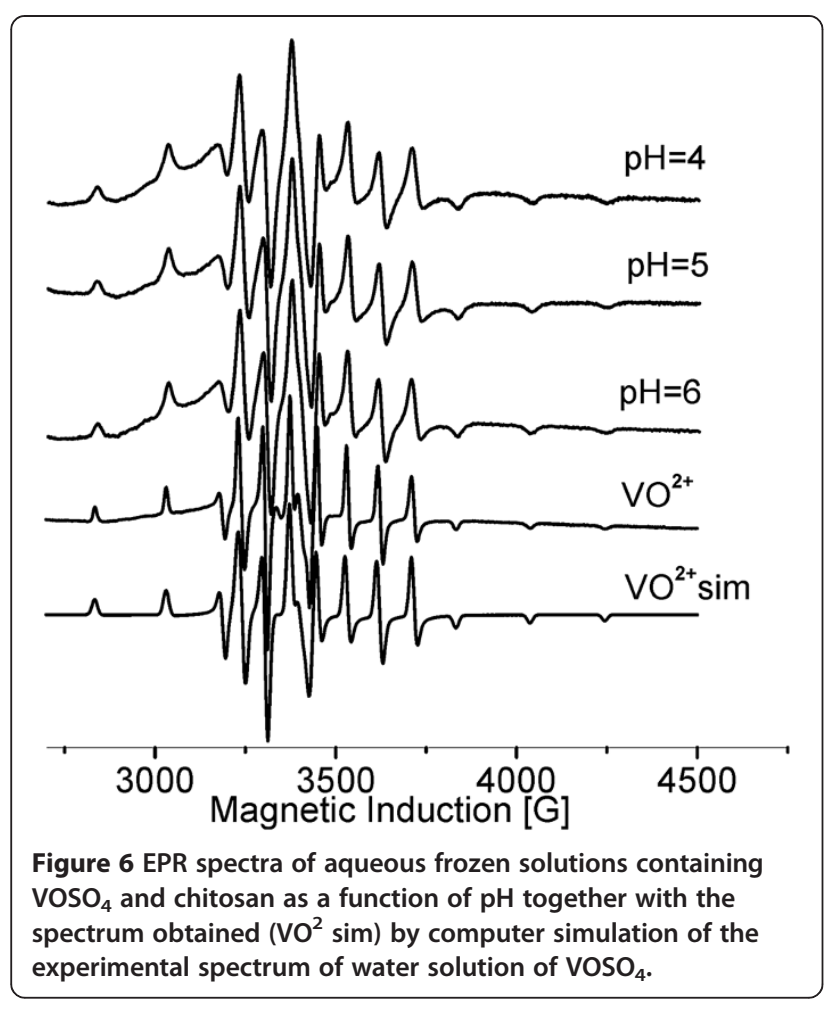

titrations are evidently disturbed by increasing aggregation of MCCh regardless DD.

\section{Methods}

\section{Materials}

MCCh (weight-average molecular weight $M_{\mathrm{w}}=2 \cdot 10^{5} \mathrm{Da}$, Institute of Biopolymers and Chemical Fibers, Łódź, Poland) was used in the form of hydrogel of definite polymer content (2.55 and $2.56 \mathrm{wt} \%)$ at two different average degrees of DD: 79.8, 97.7\%. The degree of DD, necessary to estimate the content of $-\mathrm{NH}_{2}$ groups in the samples, was determined by the method of first derivative UV-spectrophotometry (1DUVS) according to Khor and co-workers [33]. Vanadium(IV) stock solution was prepared from $\mathrm{VOSO}_{4} \times \mathrm{H}_{2} \mathrm{O}$ (Alfa Aesar $\mathrm{GmbH} \& \mathrm{Co} \mathrm{KG})$. Carbonate-free $0.1000 \pm 0.0003 \mathrm{M}$ $\mathrm{NaOH}$ solution (Mallinckrodt Baker B.V.) was used as titrant. Other reagents, i.e., nitric acid and potassium nitrate were from grade pro analysis (P.A.).

\section{Potentiometric titrations}

A Molspin instrument (Newcastle upon Tyne, England) equipped with an OSH-10-10 combined electrode (METRON, Poland), and autoburette was used for EMF measurements. All titrations were run at least in duplicate to ensure reliability of the data. The total volume of the Hamilton microsyringe in the autoburette amounted to $500 \mu \mathrm{L}$. The number of up to 100 titration points was attained by volume increments $5.0 \mu \mathrm{L}$. The titration course was controlled by MOLSPIN software. All the measurements were carried out at $25.0 \pm 0.1^{\circ} \mathrm{C}$ and ionic strength $0.1 \mathrm{~mol} \mathrm{~L}^{-1}\left(\mathrm{KNO}_{3}\right)$. The cell was standardized according to IUPAC recommendations with two buffers: $\mathrm{pH}=3.926$ (potassium hydrogen phthalate $0.05 \mathrm{M}+0.05 \mathrm{M} \mathrm{KNO}_{3}$ ) and $\mathrm{pH}=9.10$ (disodium tetraborate $0.01 \mathrm{M}+0.07 \mathrm{M} \mathrm{KNO}_{3}$ ) [34]. It follows then, that the buffer solutions were of the same ionic strength, medium and temperature as in the tested solutions. In addition, prior to each titration the electrode system had been calibrated in the $-\log \left[\mathrm{H}^{+}\right]$scale by strong acid-strong base titrations, according to the procedure recommended by Irving et al. [35]. In particular, $0.005 \mathrm{M}$ $\mathrm{HNO}_{3}$ (adjusted to $I=0.1 \mathrm{~mol} \mathrm{~L}{ }^{-1}$ by adding $\mathrm{KNO}_{3}$ ) was neutralized with carbonate-free $0.1 \mathrm{M} \mathrm{NaOH}$ at temperature $25.0 \pm 0.1^{\circ} \mathrm{C}$. The ionization product of water $\left(p K_{w}\right)$ under these conditions was 13.77 in our study and was in accordance with the references [36]. The values of standard electromotive force $\left(E_{0}\right)$, which also comprises the liquid junction potential, and slope $(s)$ from the equation $E=E_{0^{-}} s \cdot 59.16\left(-\log \left[\mathrm{H}^{+}\right]\right)$were evaluated by Superquad and Hyperquad 2008 [37-39]. The parameters, that were different from the ones obtained from the two-point cell standardization on $\mathrm{pH}$, were then inserted into the input files of the programs Superquad and Hyperquad 2008 to evaluate the overall, concentration formation constants: $\beta_{m l h}=\left[\mathrm{M}_{m} \mathrm{~L}_{l} \mathrm{H}_{h}\right] /[\mathrm{M}]^{m}[\mathrm{~L}]^{l}[\mathrm{H}]^{h}$, where: $\mathrm{M}=\mathrm{VO}^{2+}, \mathrm{L}=$ microcrystalline chitosan $(\mathrm{MCCh})$, $\mathrm{H}=$ hydrogen (proton). Goodness-of-fit was tested by two parameters: $\sigma$ (connected with the objective function $U=\sum_{i=1}^{n} W_{i} r_{i}{ }^{2}$, where $W_{i}$ - weight of the $i$-th experimental point of $n$ and $r_{i}-i$-th residual in $\left.\operatorname{EMF}\left(E_{\text {exp }}-E_{\text {theoret }}\right)\right)$ as well as by the $\chi^{2}$ statistics (test of randomness).

\section{FTIR spectrophotometric measurements}

Polymer films in absence and presence of the vanadyl ion were prepared for the use in IR studies. In the latter case the optimum L:M ratio was 5:1 just as in the potentiometric measurements. Initially a portion of 0.075 mmole of nitric (V) acid was added to 0.070 mmole of $\mathrm{MCCh}$ to dissolve the ligand. By using $0.1 \mathrm{M} \mathrm{NaOH}$ each sample was brought to definite $\mathrm{pH}$ within the range $3.0-6.8$. The formed water slurry was put on a teflon plate and left drying at room temperature. Then the polymer film was removed and used in the FTIR measurements on a Perkin Elmer FT-IR System Spectrum BX spectrophotometer. A total of 10 scans were accumulated. Spectral resolution was $\pm 4 \mathrm{~cm}^{-1}$. For comparison polymer membranes with chitosan in absence of the metal were prepared as well. Separately, the IR spectra of $\mathrm{VO}^{2+}$ ion were taken in $\mathrm{KBr}$ pellets. 


\section{EPR measurements}

The EPR spectra were measured using a Bruker Elexsys E500 spectrometer equipped with NMR teslameter (ER 036TM) and frequency counter (E 41 FC) at X-band. The simulations of the experimental spectra were performed using computer program WINEPR Simfonia, version 1.26 beta and the program written by Dr Andrew Ozarowski from NHMFL, University of Florida, with resonance field calculated by diagonalization of energy matrix. The spectra were measured with a modulation frequency $100 \mathrm{kHz}$, modulation amplitude of 7 gauss and microwave power of $10 \mathrm{~mW}$. The MCCh ligand (L) and $\mathrm{VO}^{2+}$ concentrations were $C_{\mathrm{L}}=7.0 \times 10^{-3} \mathrm{M}$ and $C_{\mathrm{VO} 2+}=8.75 \times 10^{-4} \mathrm{M}$, respectively. In order to avoid aggregation of $\mathrm{VO}(\mathrm{IV})$ complexes in water $10 \%(\mathrm{v} / \mathrm{v})$ of ethyl glycol was added to the studied solutions.

\section{Abbreviations}

DD: Degree of deacetylation; FTIR: Fourier-transform infrared spectroscopy; EPR: Electron paramagnetic resonance; $L=M C C h$ : Microcrystalline chitosan as ligand; M: Oxovanadium (IV) ion as metal; L/M: The ligand-to-metal concentration ratio; $a$ : mmole of base/mmole of ligand; $\beta_{m / h}=\left[M_{m} L_{l} H_{h}\right] /[M]^{m}[L]^{\prime}[H]^{h}$ : Cumulative stability constant; $m, l$, h: Number of metals (central ions), ligands and protons, respectively; concentrations in square brackets are equilibrium concentrations.

\section{Competing interests}

The authors declare that they have no competing interest.

\section{Authors' contributions}

All authors contributed equality for the development of the manuscript. MEL carried out the potentiometric and FTIR spectroscopic analysis, participated in the results discussion. KHB interpreted the spectral data and revised the manuscript. JJ carried out and interpreted the EPR data. AK proposed the research idea and coordinated final formulation. The authors read and approved the final manuscript.

\section{Acknowledgements}

Financial support of this work by the Medical University of Łódź (Project 502-03/3-014-02/502-34-005 - M.E. Lichawska and Statute Funds No. 503/3-014-02/503-01 - A. Kufelnicki), No. 503/3-021-01/503-01 - K.H. Bodek is kindly acknowledged.

\section{Author details}

'Department of Physical and Biocoordination Chemistry, Faculty of Pharmacy, Medical University of Łódź, 90-151 Łódź, Poland. ${ }^{2}$ Chair of Applied Pharmacy, Faculty of Pharmacy, Medical University of Łódź, 90-151 Łódź, Poland. ${ }^{3}$ Faculty of Chemistry, University of Wrocław, 50-383 Wrocław, Poland.

Received: 8 May 2014 Accepted: 31 July 2014 Published online: 09 September 2014

\section{References}

1. Ravi Kumar MNV, Muzzarelli RA, Muzzarelli A, Sashiwa CH, Domb A: Chitosan Chemistry and Pharmaceutical Perspectives. Chem Rev 2004, 104:6017-6084.

2. Baran EJ: Spectroscopic investigation of the $\mathrm{VO}^{2+} /$ chitosan interaction Carbohydr Polym 2008, 74:704-706.

3. Baran EJ: Oxovanadium(IV) complexes of carbohydrates: A brief overview. $J$ Inorg Biochem 2009, 103:547-553.

4. Rowe RC, Sheskey PJ, Quinn ME: Handbook of Pharmaceutical Excipients. 6th edition. London UK: Pharmaceutical Press; 2009.

5. Roberts GA: Chitin Chemistry. Hongkong: Macmillan Publishers Limited; 1992:203.
6. Säkkinen M, Marvola J, Kanerva H, Lindevall K, Lipponen M, Kekki T, Ahonen A, Marvola M: Gamma scintigraphic evaluation of the fate of microcrystalline chitosan granules in human stomach. Eur J Pharm Biopharm 2004, 57:133-143.

7. Säkkinen M, Marvola J, Kanerva H, Lindevall K, Ahonen A, Kekki T, Marvola M: Are chitosan formulations mucoadhesive in the human small intestine? An evaluation based on gamma scintigraphy. Int J Pharm 2006, 307:285-291.

8. Struszczyk H: Microcrystalline chitosan. Preparation and properties of microcrystalline Chitosan. J Appl Polym Sci 1987, 33:177-189.

9. Baran EJ: Review: Spectroscopic studies of oxovanadium coordination compounds. J Coord Chem 2001, 54:215-238.

10. Kofuji K, Qian CJ, Murata Y, Kawashima S: The controlled release of insulin-mimetic metal ions by the multifunction of chitosan. J Inorg Biochem 2005, 99:1329-1334.

11. Thomson KH, Orvig C: Vanadium in diabetes: 100 years from Phase 0 to Phase I. J Inorg Biochem 2006, 100:1925-1935.

12. Thomson KH, Lichter J, LeBel C, Scaife MC, McNeill H, Orvig C: Vanadium treatment of type 2 diabetes: a view to the future. J Inorg Biochem 2009, 103:554-558.

13. Parajón-Costa BS, Baran EJ: Vibrational spectra of bis(maltolato)oxovanadium (IV): A potent insulin mimetic agent. Spectrochim Acta A Mol Biomol SpectrosC 2011, 78:133-135.

14. Sanna D, Bíró L, Buglyó P, Micera G, Garriba E: Transport of the anti-diabetic $\mathrm{VO}^{2+}$ complexes formed by pyrone derivatives in the blood serum. J Inorg Biochem 2012, 115:87-89.

15. Sanna D, Bíró L, Buglyó P, Micera G, Garriba E: Coordinating Properties of Pyrone and Pyridinone Derivatives, Tropolone and Catechol toward the $\mathrm{VO}^{2+}$ Ion: An Experimental and Computational Approach. Eur J Inorg Chem 2012, 1079-1092.

16. Várnagy K, Csorba T, Kiss D, Garriba E, Micera G, Sanna D: VIVO Complexes of Bis(imidazol-2-yl) Derivatives: A Potentiometric, Spectroscopic and DFT Study. Eur J Inorg Chem 2007, 4884-4896.

17. Pisano L, Kiss D, Várnagy K, Sanna D, Micera G, Garriba E: Potentiometric, Spectroscopic and DFT Study of the VIVO Complexes Formed by Di (pyridin-2-yl) Ligands. Eur J Inorg Chem 2009, 2362-2374.

18. Kiss T, Kiss E, Garriba E, Sakurai H: Speciation of insulin-mimetic VO(IV)-containing drugs in blood serum. J Inorg Biochem 2000, 80:65-73.

19. Jansson-Charrier M, Guibal E, Roussy J, Delanghe B, Le Cloire P: Vanadium (IV) sorption by chitosan: kinetics and equilibrium. Water Res 1996, 30:465-475.

20. Bodek KH, Kufelnicki A: Protolytic and Complexing Properties of Microcrystaline Chitosan with Co(II), Zn(II), and Cu(II) lons. J Appl Polym Sci 1995, 57:645-651.

21. Bodek KH, Kufelnicki A: Interaction of microcrystalline chitosan with Ni(II) and Mn(II) ions in aqueous solution. J Appl Polym Sci 2005, 98:2572-2577.

22. Lichawska ME, Kufelnicki A, Bodek KH: Coordinative interaction of microcrystalline chitosan (MCCh) with $\mathrm{Ca}$ (II) and $\mathrm{Mg}(\mathrm{II})$ in aqueous solution. Clin Exp Med Lett 2010, 51:69-73.

23. Kufelnicki A, Lichawska M, Bodek KH: Interaction of Microcrystalline Chitosan (MCCh) with Mo(VI) in Aqueous Solution. J Appl Polym Sci 2009, 114:1619-1625.

24. Henry RP, Mitchell PCH, Prue JE: Hydrolysis of the Oxovanadium(1v) lon and the Stability of its Complexes with the I ,2-Dihydroxybenzenato(2-) Ion. J Chem Soc Dalton Trans 1973, 1156-1159.

25. Komura A, Hayashi M, Imanaga H: Hydrolytic Behavior of Oxovanadium(IV) Ions. Bull Chem Soc Jpn 1977, 50:2927-2931.

26. Rossotti FJC, Rossotti HS: Studies on the Hydrolysis of Metal lons, XII. The Hydrolysis of the Vanadium(IV) ion. Acta Chem Scand 1955, 9:1177-1192.

27. Berto S, Giuseppe PD, Diana E, Laurenti E, Prenesti E: Thermodynamic, spectroscopic and DFT description of oxidovanadium(IV) complexes with malate and tartrate in aqueous solution. Inorg Chim Acta 2014, 414:105-114.

28. Lodyga-Chruscinska E, Sanna D, Garribba E, Micera G: Potentiometric, spectroscopic, electrochemical and DFT characterization of oxovanadium (IV) complexes formed by citrate and tartrates in aqueous solution at high ligand to metal molar ratios: the effects of the trigonal bipyramidal distortion in bis-chelated species and biological implications. Dalton Trans 2008, 36:4903-4916.

29. Lodyga-Chruscinska E, Szebesczyk A, Sanna D, Hegetschweiler K, Micera G, Garribba E: Formation in aqueous solution of a non-oxido V(IV) complex with VN6 coordination. Potentiometric, ESI-MS, spectroscopic and computational characterization. Dalton Trans 2013, 42:13404-13416.

30. Schatz C, Viton C, Delair T, Pichot C, Domard A: Typical physicochemical behaviors of chitosan in aqueous solution. Biomacromolecules 2003, 4:641-648. 
31. Taboada E, Cabrera G, Cardenas G: Retention Capacity of Chitosan for Copper and Mercury lons. J Chilean Chem Soc 2003, 48:7-12.

32. Hadi AG: Adsorption of Nickel lons By Synthesized Chitosan. Brit J Sci 2012, 6:109-113.

33. Tan SC, Khor E, Tan Teck K, Wong Sek M: The degree of deacetylation of chitosan: advocating the first derivative UV-spectrophotometry method of determination. Talanta 1998, 45:713-719.

34. Buck RP, Rondinini S, Covington AK, Baucke FGK, Brett CMA, Camões MF, Milton MJT, Mussini T, Naumann R, Pratt KW, Spitzer P, Wilson GS: Measurement of pH. Definition, standards, and procedures. Pure Appl Chem 2002, 74:2169-2200.

35. Irving HM, Miles MG, Pettit LD: A study of some problems in determining the stoicheiometric proton dissociation constants of complexes by potentiometric titrations using a glass electrode. Anal Chim Acta 1967, 38:475-488.

36. Zekany L, Nagypal: PSEQUAD: A Comprehensive Program for the Evaluation of Potentiometric and/or Spectrophotometric Equilibrium Data Using Analatylical Derivatives. In Computational Methods for the Determination of Stability Constants. Plenum Press; New York: David J. Leggett; 1985:352.

37. Gans P, Sabatini A, Vacca A, SUPERQUAD: an improved general program for computation of formation constants from potentiometric data. Journal of the Chemical Society, Dalton Transactions 1985, 1195-1200.

38. Sabatini A, Vacca A, Gans P: Mathematical algorithms and computer programs for the determination of equilibrium constants from potentiometric and spectrophotometric measurements. Coord Chem Rev 1992, 120:389-405.

39. Gans P, Sabatini A, Vacca A: Investigation of equilibria in solution. Determination of equilibrium constants with the HYPERQUAD suite of programs. Talanta 1996, 43:1739-1753.

doi:10.1186/s13065-014-0050-7

Cite this article as: Lichawska et al: Coordinative interaction of microcrystalline chitosan with oxovanadium (IV) ions in aqueous solution. Chemistry Central Journal 2014 8:50.

\section{Publish with ChemistryCentral and every scientist can read your work free of charge \\ "Open access provides opportunities to our colleagues in other parts of the globe, by allowing anyone to view the content free of charge." \\ W. Jeffery Hurst, The Hershey Company. \\ - available free of charge to the entire scientific community \\ - peer reviewed and published immediately upon acceptance \\ - cited in PubMed and archived on PubMed Central \\ - yours - you keep the copyright \\ Submit your manuscript here: \\ http://www.chemistrycentral.com/manuscript/<smiles>c1ccccc1</smiles> 